\title{
RESENHA
}

\section{Antônio César Ortega. Territórios Deprimidos - desafios para as políticas de desenvolvimento rural, Uberlância, Edufu, 2008}

\section{Elaborada por Armando Lírio de Souza ${ }^{1}$ e Lucia Cristina Gama de Andrade $^{2}$}

Territórios Deprimidos - desafios para as políticas de desenvolvimento rural é resultado dos estudos de pós-doutorado do professor Antonio César Ortega, da Universidade Federal de Uberlândia, apresentada ao Programa de Pós-Graduação do Instituto de Economia da Universidade Estadual de Campinas (2006-2007). É uma obra que visa atender a alunos de diferentes áreas do conhecimento, abordando, de forma multidisciplinar, o planejamento no tempo e no espaço, acompanhando a evolução do conceito de desenvolvimento tal como empreendido pelos diferentes países que passaram por essa experiência, e fazendo um resgate teórico do uso do enfoque territorial. Trata-se de uma obra de grande relevância para a temática do desenvolvimento rural, principalmente por destacar a utilização da abordagem territorial nas políticas de desenvolvimento rural, bem como pela análise das potencialidades e limites desse conceito, especialmente no contexto da América Latina. O autor parte de uma pergunta crucial para tentar entender a opção da ação governamental contemporânea por um

1 Professor da Faculdade de Economia, Instituto de Ciências Sociais Aplicadas, Universidade Federal do Pará/UFPA e doutorando da Universidade Federal do Rio Grande do Sul/ UFRGS

2 Mestre em Planejamento do Desenvolvimento/PLADES/NAEA/UFPA, pesquisadora no Núcleo de Altos Estudos Amazônicos, Universidade Federal do Pará/NAEA/UFPA. 
projeto de desenvolvimento endógeno centrado na introdução de arranjos socioprodutivos locais.

O território deve ser compreendido como espaço resultante de relações sociais, locus de luta política e palco de dinâmicas multidimensionais. Ortega (2008) aponta para a busca do desenvolvimento de forma autônoma e endógena, como recomendado pelas agências multilaterais, as quais reconhecem, no entanto, que, na segunda metade do século XX, países que tiveram suas estratégias de crescimento centradas na melhoria de distribuição de renda e ativos, ficaram em melhor situação, ao contrário daqueles que buscavam o desenvolvimento de base localista e que embaçaram o papel do Estado por causa da onda liberalizante e descentralizadora das políticas públicas a partir da base territorial. As recomendações das agências influenciaram sobremaneira a atuação de atores locais na construção de políticas públicas e preconizaram a eficiência da gestão pública centrada na endogenia do desenvolvimento. $\mathrm{O}$ autor afirma, contudo, que as transferências de responsabilidades não são acompanhadas de meios para sua execução. Desse modo mantém-se a distribuição assimétrica dos recursos que conservam ou agravam disparidades regionais. Na obra de Ortega, é possível perceber dois elementos altamente complexos e significativos para uma melhor compreensão das iniciativas de descentralização territorial na América Latina: a ação social-liberal dos anos 90, preocupada com o livre mercado e o estabelecimento de vantagens comparativas e o posicionamento dos movimentos sociais na luta pela autonomia dos espaços subnacionais como base dos processos de democratização. Essas duas vertentes, normalmente, tornam-se paradoxais devido a sua forte tendência localista. Seus partidários muitas vezes assumem em seus discursos a valorização dos "espaços de concertação para a construção de projetos locais com vistas ao desenvolvimento" (ORTEGA, 2008, p.14). O grande mérito de Ortega é apontar claramente a influência da posição dos atores militantes e das agências multilaterais na "construção de uma nova cidadania". De certa forma, ele ressalta as sequelas provocadas pelas teses localistas na vulgarização da temática territorial, atribuindo-lhe o papel de divulgar 
modelos de comportamento e recomendações de estratégias para as ações governamentais no campo do desenvolvimento econômico e social. O autor também discute questões relacionadas a um possível mito da territorialização e da desterritorialização, propondo um conceito de "des(re) territorialização" que se fundamenta na reconstrução constante das base territoriais. Isso representaria manter um alto grau de experimentação, objetivando apreender a complexidade e heterogeneidade da ruralidade. As políticas de desenvolvimento rural têm sido, normalmente, pautadas pelo combate à pobreza rural, por um forte viés de mercantilização, por incentivo a processos de inovação institucional e tecnológica e pela reformas no aparelho de Estado (governança).

Essas orientações influenciaram diretamente o poder e os atores locais, pois pareciam trazer a garantia de eficiência e agilidade na gestão pública; tinham, pois, um caráter puramente normativo centrado na "perspectiva endogenista do desenvolvimento". O fato concreto observado por Ortega (2008) é a proliferação das políticas de desenvolvimento rural e desdobramentos capazes de levar ao discurso da inexorável implantação de projetos inclusivos e a criação de condições propícias para a instalação de arranjos socioprodutivos (projetos coletivos de desenvolvimento local). Em suma, o risco maior é cair novamente na armadilha do mito do desenvolvimento, enveredar por práticas com o objetivo de desconsiderar o ambiente macroeconômico, relativizar os conflitos de classes, minimizar o papel do espaço e das políticas nacionais e mergulhar em uma interpretação a-histórica. Dessa forma, o autor alerta para o fato de que o enfoque territorial não pode ser tomado como panacéia para o resgate histórico da exclusão social e de inserção produtiva.

Ortega propõe compreender a importância da abordagem territorial como um elemento capaz de explicitar os conflitos sociais; assim, recupera a preocupação com as relações de poder no interior do território e nas suas relações externas. Para ele a construção de uma cultura cooperativista ou a estabilidade das relações comunitárias é algo fundamental na capacidade de gerar desenvolvimento endógeno. 
As condições de enraizamento das relações sociais estariam mais estabilizadas no âmbito da agricultura familiar. Dessa maneira, os arranjos socioprodutivos não seriam meros produtos do acaso ou formulações do receituário das agências multilaterais, mas consistiriam em campos de resistência por meio de práticas cooperativas e comunitárias ou da habilidade social dos atores, constituída ao longo de sua trajetória política e produtiva no território. Portanto, haveria a construção de novas formas de articulação territorial em escalas variadas. No entanto, isso não significaria o fim do papel do Estado ou de políticas públicas pró-ativas, face às condições de precariedade e vulnerabilidade social dos territórios, daí a expressão "territórios deprimidos". O que o autor chama de "Territórios Economicamente Deprimidos" são aqueles constituídos por municípios com baixo nível de desenvolvimento, baixo ritmo de crescimento e baixo potencial de desenvolvimento. E ainda que esse conceito também seja utilizado pela União Européia, cai como uma luva para tratar do desenvolvimento rural dos territórios brasileiros, principalmente aqueles da região norte e nordeste e, por extensão, outros situados na América Latina, cujos indicadores sociais (educação, saúde e mortalidade) estão abaixo da média nacional assim como sua capacidade institucional.

A revisão da literatura realizada pelo autor no campo de conceitos como capital social e instituições abrange referenciais da nova economia institucional, da nova sociologia econômica e de autores da sociologia crítica como Pierre Bourdieu. Em relação às noções de conceitos de território e territorialidade são citados autores do campo da geografia como David Havey e Rogério Haesbaert. Esse caráter pluralista da análise permite ao autor a proposição de pactos territoriais rurais e a importância dos atores sociais coletivos. Nesse sentido, direciona sua interpretação para a importância da agricultura familiar e a necessidade de fortalecer suas organizações.

Percebe-se no autor a ênfase na participação dos atores sociais coletivos, mesmo considerando o alto grau de autonomia e individualismo presente na agricultura familiar, agora voltados para a emergência de organizações 
por produtos, portanto, em parte superando os modelos corporativos de ação sindical. Nas palavras do próprio autor: "ao se fomentar uma cultura de maior organização social, pode-se, em determinadas condições, criar situações mais propícias e favoráveis de desenvolvimento e de inclusão econômica e social. É assim, que, de uma perspectiva otimista, os arranjos produtivos locais/territoriais, transformam-se num espaço de aglutinação de forças capazes de superar os conflitos e de construir um consenso que viabilize um pacto territorial pelo desenvolvimento" (ORTEGA, 2008, p. 63). A problemática reside em construir um consenso, em um campo de conflitos e diferenças, capaz de representar os vários interesses ou o sentido multidimensional do território, uma tarefa de alta complexidade e dificuldade. No entanto, o estabelecimento de arranjos socioprodutivos locais, principalmente aqueles protagonizados pelos atores sociais coletivos da agricultura familiar não podem ser caracterizados como meras reproduções de iniciativas normativas. Isso seria simplificar demais a análise, por isso, insisto em compreendê-los no campo de resistências.

$\mathrm{Na}$ visão de Ortega (2008), as ações coletivas para a inserção no mercado não aparecem como algo problemático, pois "ao se falar em alternativa para a agricultura familiar, deve-se pensar em sua capacidade de organização para atender as exigências do mercado. Em outras palavras, é necessário elevar a capacidade de organização desses agricultores para uma melhor inserção nos mercados de forma a reduzir o caráter parcial e excludente do desenvolvimento rural latino-americano" (ORTEGA, 2008, p. 110). A princípio, isso não representaria uma noção mercantilista ou produtivista. Na verdade, o autor adota a noção de mercado construído socialmente, mas parece não compartilhar da noção de iniciativas espontâneas, principalmente ao destacar a importância do papel do Estado no fomento aos territórios deprimidos. Portanto, hipoteticamente, considera as ações dos atores coletivos locais resultantes tanto de ações espontâneas como de ações induzidas de desenvolvimento local ou desenvolvimento territorial rural. 
O fôlego interpretativo do autor lhe permite construir uma síntese do termo desenvolvimento, recuperar a constituição dos arranjos socioprodutivos na América Latina, analisar políticas de desenvolvimento territorial rural, problematizar o novo rural brasileiro e revitalizar os conflitos de classes no rural. Finalmente analisa os efeitos da descentralização das políticas públicas brasileiras no âmbito do desenvolvimento territorial rural, como o Programa Nacional de Apoio a Agricultura Familiar (PRONAF) e a condição de institucionalidade dos Conselhos Municipais de Desenvolvimento Rural Sustentável (COMDRS). Tece comentários e organiza dados sobre as políticas mais recentes como os Territórios da Cidadania e os Consórcios Intermunicipais de Segurança Alimentar e Desenvolvimento Local (CONSAD’s). Sinaliza que a intervenção estatal é fundamental na promoção de infraestrutura socioprodutiva básica para fomentar o desenvolvimento dos territórios deprimidos, que encontram entraves quanto à capacidade de geração de desenvolvimento endógeno, vide a criação no Brasil, dos territórios da Cidadania. O autor suscita assim, a busca de um pensar sobre as estratégias de desenvolvimento, em especial para tais territórios que, dentro de suas realidades, estão a esperar o "trem da história”. O objetivo é apreender a heterogeneidade econômica e social e argumentar pela construção do pacto territorial, na atual conjuntura da América Latina, e pela emergência de novas instituições para a promoção do desenvolvimento territorial, criando possibilidades para retirar dos territórios a condição de deprimidos. 